\title{
Positivity in Mental and Physical Health
}

\author{
Urvashi Sharma 1 , Dr. Ravindra Kumar 2
}

\section{ABSTRACT:}

Health is a state of complete physical, mental and social well-being and not merely the absence of disease or infirmity. Mental health refers to our overall psychological well-being. It includes the way we feel about our self, the quality of our relationships, and our ability to manage our feelings and deal with difficulties. Good mental health isn't just the absence of mental health problems. People who are emotionally or mentally healthy are in control of their emotions and their behavior. They are able to handle life's challenges, build strong relationships, and recover from setbacks. Positive mental health is a state of well-being in which we realize our abilities, can cope with life's normal stresses, and can work regularly and productively. Physical health means a good body health, which is healthy because of regular physical activity, good nutrition, and adequate rest. Physical health can be determined by considering someone's height/weight ratio, their Body Mass Index. Another term for physical health is physical wellbeing. Physical wellbeing is defined as something a person can achieve by developing all health-related components of his/her lifestyle. It can be concluded that mental and physical health is fundamentally linked. There are multiple associations between mental health and chronic physical conditions that significantly impact people's quality of life. Just as physical fitness helps our bodies to stay strong, mental fitness helps us to achieve and sustain a state of good mental health. When we are mentally healthy, we enjoy our life and environment, and the people in it.

Keywords: Health, mental health, physical health, quality of life and physical wellbeing.

\section{INTRODUCTION:}

Today, we are living in such a scientific era in which development and progress at their high peak but when we see the dark side behind this our overall health is also affecting due to this rapid development and progress, whether it is physical health, mental health or social health. If we analysis the objectives behind our life activity we find that all types of behaviors conducted by us, whether physical behavior, mental behavior or social behavior, is only for the fulfillment of our needs.

\footnotetext{
${ }^{1}$ Indian Institute of Psychology, Noida, U.P.

${ }^{2}$ Department of Psychology, Mewar University, Chittorgarh, Rajasthan
}

(C) 2015, U Sharma, R Kumar; licensee IJIP. This is an Open Access Research distributed under the terms of the Creative Commons Attribution License (http://creativecommons.org/licenses/by/2.0), which permits unrestricted use, distribution, and reproduction in any Medium, provided the original work is properly cited. 


\section{Psychological Well-being among public and private undertakings in Aligarh}

Thus we can say that it is the subject of social thinking that positive aspects should be elaborated in relation to mental health and social health so that we can provide good positive mental, physical and social health to the society. In the absence of any one of these types of health the development, progress, social relations, human behaviors of any country may be affected or disturbed on a large scale.

In the present paper we have focused on mental and physical health in relation to positive and constructive aspects.

In 1948 the World Health Organization (WHO) defined health as 'a complete state of physical, mental and social well-being and not merely the absence of disease or infirmity'. This definition broke ground for three reasons:

- It is a positive definition, rather than a negative one - health is not merely the absence of illness.

- It recognized various dimensions of health status, including mental, physical and social aspects.

- It included political and social considerations, and was therefore inspirational. For example, well-being might require the elimination of poverty and freedom, enabling people to live in a society with social justice.

However, under this definition it is difficult for very many people to be categorized as healthy. Furthermore, it has been criticized because it is idealistic and utopian (Seedhouse, 1986). In summary, disenchantment with the biomedical model, and an increasing focus on social and psychological influences on health, led to the development of the biopsychosocial model (Engel, 1977).

\section{MENTAL HEALTH AND POSITIVITY}

\section{Concept of Mental health}

Mental health refers to our overall psychological well-being. It includes the way we feel about our self, the quality of our relationships, and our ability to manage our feelings and deal with difficulties. Good mental health is not just the absence of mental health problems. Being mentally healthy is much more than being free of depression, anxiety, or other psychological issues. Rather than the absence of mental illness, mental health refers to the presence of positive characteristics.

People who are mentally healthy are in control of their emotions and their behavior. They are able to handle life's challenges, build strong relationships and recover from setbacks in their environment but just as it require effort to build or maintain physical health, so it is with mental and emotional health. Improving your mental health can be a rewarding experience, benefiting all aspects of your life, including boosting our mood, building resilience, and adding to our overall enjoyment of life. 


\section{Positive Mental Health and its maintenance}

Positive mental health is a state of well-being in which we realize our abilities, can cope with life's normal stresses, and can work regularly and productively. Good mental health is the foundation for a person's effective functioning. As a member of the military, familiarity with stress management skills and maintaining a healthy lifestyle can help you reduce depression, prevent a progression to posttraumatic stress disorder (PTSD), and may also reduce the chances of diminished work performance, obesity and injury.

\section{Psychological Wellness}

Psychological wellness is not just the absence of mental disorders. It is:

- Being comfortable with ourself

- Feeling good about ourself

- Being able to meet the demands of life situations

- Being able to express emotion in healthy ways

- Being able to cope with the stress of daily life

Our physical health is intimately connected to our psychological wellness. Research shows that our attitude affects our brain, body and emotions. Adopting attitudes that incorporate gratitude, appreciation and love can have a profound effect on our body's health. A positive attitude should be part of our daily wellness practice.

Psychological benefits include enhanced general wellbeing, body image, self-esteem and self-perceptions (Moses et al., 1989); improved general cognitive functioning among older adults reduced emotional distress and reduced depression. It is important to note that physical activity does not simply take away or minimize disease but enhances positive health within individuals. For example, many individuals experience an increase in positive affect and wellbeing after participating in activity. The 'feel good factor' or the 'runner's high' is a common response as to why people exercise and these intense positive emotions can be experienced in acute and chronic forms. Linking to the broaden-and-build theory of positive emotions (Fredrickson, 2001), PA enhances levels of positive affectivity, thereby enabling individuals to build psychological, social, intellectual and physical resources (Kobasa et al., 1985).

\section{Positive and Constructive Factors in Mental Health}

Enjoying mental health means having a sense of wellbeing, being able to function during everyday life and feeling confident to rise to a challenge when the opportunity arises. Just like our physical health, there are actions we can take to increase our mental health. Some positive constructive factors can boost our mental health and wellbeing such as:

- Development of Good Relationship: We should develop and maintain strong and good relationships with people around us and in our society who will support and enrich our life. The quality of our personal relationships has a great effect on our wellbeing. Putting time and effort into building strong relationships can bring great rewards in relation to positivity in mental health. 
- Participation and Sharing of Interests: We can join a club or group of people who share our interests. Being part of a group of people with a common interest provides a sense of belonging and is good for our mental health.

- Contribution to Community: Volunteer your time for a cause or issue that you care about. Help out a neighbor, work in a community garden or do something nice for a friend or relative. There are many great ways to contribute that can help you feel good about yourself and your place in the world. An effort to improve the lives of others is sure to improve your life too.

- Challenge Yourself: We can learn a new skill or take on a challenge to meet a goal. You could take on something different at work commit to a fitness goal or learn to cook a new recipe. Learning improves your mental fitness, while striving to meet your own goals builds skills and confidence and gives you a sense of progress and achievement.

- Dealing with daily Psychological problems: Be aware of what triggers our stress and how we react. We may be able to avoid some of the triggers and learn to prepare for or manage others. Stress is a part of life and affects people in different ways. It only becomes a problem when it makes us feel uncomfortable or distressed. A balanced lifestyle can help us manage stress better.

- Rest and Refreshment: Get plenty of sleep. Go to bed at a regular time each day and practice good habits to get better sleep. Sleep restores both your mind and body. However, feelings of fatigue can still set in if you feel constantly rushed and overwhelmed when you are awake.

\section{Benefits of Good Mental Health}

Just as physical fitness helps our bodies to stay strong, mental fitness helps us to achieve and sustain a state of good mental health. When we are mentally healthy, we enjoy our life and environment, and the people in it whether it is personal environment or social environment. We can be creative, learn, try new things, and take risks. We are better able to cope with difficult times in our personal and professional lives. We feel the sadness and anger that can come with the death of a loved one, a job loss or relationship problems and other difficult events, but in time, we are able to get on with and enjoy our lives once again.

\section{PHYSICAL HEALTH AND POSITIVITY}

\section{Concept of Physical Health}

Physical health can be determined by considering someone's height/weight ratio, their body mass index (BMI), their resting heart rate and recover time after exercise. For humans, physical health means a good body health, which is healthy because of regular physical activity, good nutrition, and adequate rest.

\section{Physical Wellbeing}

Another term for physical health is physical wellbeing. Physical wellbeing is defined as something a person can achieve by developing all health-related components of his/her lifestyle. 


\section{Psychological Well-being among public and private undertakings in Aligarh}

Fitness reflects a person's cardio respiratory endurance, muscular strength, flexibility, and body composition. Other contributors to physical wellbeing may include proper nutrition, bodyweight management, abstaining from drug abuse, avoiding alcohol abuse, responsible sexual behavior (sexual health), hygiene, and getting the right amount of sleep.

Physical activity (PA) and positive psychology are a match made in heaven - one focuses on the building of happy, fully functioning people (positive psychology) and the other is a tried and tested avenue for creating such positive people (physical activity). Not only does physical activity enhance physical functioning, thereby reducing the risks of disease but it can also make us happier, more energized, confident, self-regulated individuals and even make us smarter (Ratey, 2008). Physical activities help us to maintain a balance between mental and physical health, we can say that it is the unique element of psychophysical wellbeing.

American Indian women in the USA have been shown to hold quite different concepts of health from Western medical views. For example, in her study with Native American women, Canales (2004, p. 420) shows how health is viewed as a balance between mind, body and spirit. If we conclude this study we find that it is just like psychophysical wellbeing.

In an early influential study on lay health beliefs, Herzlich (1973) interviewed eighty middle-class adults living in Paris or Normandy in France. These people were not 'ill' but from a 'healthy' section of the population. Three distinct dimensions of health were clear in her interviews:

- Health in a vacuum: health is an absence of illness, and is only paid attention when it is lost through illness of some kind. Here health can be viewed as an objective fact.

- Reserve of health: health is seen as a kind of asset which enables a person to resist illness and maintain good health. Thus, it can be spent or renewed. Here health can be viewed as an individual difference, with some people having more of it and others having less. How much health a person has in reserve is viewed as something he or she is born with, but also as something that can change over time.

- Equilibrium: health is defined as dependent on positive feelings and good relationships with others. If life is going well, a state of equilibrium is present.

Here, health involves comparison with others to determine whether things are going well and whether life is in balance. This study partially supported the WHO definition of health that health as a complete state of physical, mental and social wellbeing. Generally, if we analyze the structure of health we also find that it is the combination of physical, mental and social wellbeing.

Another study on people's ideas about health in France was conducted by Pierret (1995). In this study, over a hundred people from a range of backgrounds participated in an interview and completed a questionnaire in which they gave information about their health and behavior related to health. Pierret identified four ways in which people talked about health:

- Health is not being ill: illness is used as a referent for health. This way of talking about health was used by people from all Socio Economic Status (SES) backgrounds. 
- Health is the most important thing: the yardstick to compare the rest of life with, people's wealth and capital. This concept was employed by a quarter of the participants, primarily those from lower SES groups.

- Health as a product: the view that health depends on behavior, living conditions, social system, and can be controlled. Health was seen as a value in this way by two out of ten people living in urban areas, primarily by older people from higher Socio Economic Status (SES) SES groups.

- Health as an institution: health was viewed through social structures and medical institutions, which are responsible for collective health. Young educated participants talked about health in this way.

This study again highlighted how people see health in different ways depending on their social situation. Pierret (1995) concludes by commenting that the right to health is being replaced by an obligation to be healthy. These three views of health are ordered so that we can think about health from absence to presence, from impersonal to personal and from fact to norm (Radley, 1994). Herzlich's study demonstrated that health was more than the absence of illness, and more than the 'opposite of being ill'. It was inherently tied into people's lives, including their social relationships, life events and activities.

\section{Positive and Constructive Factors in Physical Health}

Although positive or constructive factors for both types of health are similar yet the following tips may be helpful to maintain a physical health:

- Balanced Diet and Nutrition: Health care practitioners will tell you that you have to provide your physical body with high quality fuel if you want it to run properly. Eat a healthy, chemical-free diet high in vital nutrients. Take the herbal and vitamin supplements that will support you in your good health.

- Adequate Rest: Get the appropriate amount of uninterrupted sleep you need to engage your REM patterns. REM sleep is your nervous system's way of healing and refueling your body. Also, if you're feeling overly sluggish, take a short nap or sit and rest. Chronic sleep and sluggishness problems should be reported to your health care provider.

- Focused on Present: Feelings of regret or worry about a past event or worry and anxiety about an upcoming future event are not only a waste of your precious life time. They also add stress to the body which makes you more susceptible to disease. Stay present and focused on the beauty and gifts this moment is offering you.

- Physical Exercise: Exercise is known to help you live a longer and healthier life. The body needs to stay in action and movement.

- Psychological Exercise: A healthy physical body includes a sound and sharp mind. Keep challenging your mind to expand, grow, learn experience, decipher, and explore.

- Yoga and Meditation: Not only is meditation simple and fun, it also has been known to reduce your heart rate, reduce your stress level, help you become present in this moment, increase your feelings of peace, serenity, joy, and spiritual faith. 


\section{CONNECTION BETWEEN MENTAL AND PHYSICAL HEALTH}

Mental and physical health is fundamentally linked. There are multiple associations between mental health and chronic physical conditions that significantly impact people's quality of life, demands on health care and other publicly funded services, and generate consequences to society. The World Health Organization (WHO) defines: health as a state of complete physical, mental and social well-being and not merely the absence of disease or infirmity. The WHO states that "there is no health without mental health."

The relationship between mind and health is mediated both by our behavior and by biological connections between the brain and immune system. That these connections work in both directions, so our physical health can influence our mental state. All illnesses have psychological and emotional consequences as well as causes. There is nothing shameful or weak about the intrusion of thoughts and emotions into illness. Our social relationships with other people are central to health. That our dualist habit of contrasting mind and body, as though they were two fundamentally different entities, is deeply misleading (Martin, 1997, p. 314). The psychology of health, illness and health care needs to be considered in economic, political, ecological, social and cultural context. (Marks et al., 2000, p. 1)

Strong family relationships are vital to overall health. However, there is no perfect family or perfect relationship. Many military families struggle with common issues. The key to wellness is how you handle problems and support one another. There will inevitably be times when stress, adversity or trauma negatively affects your sense of well-being. During these difficult times, it is healthy, and advisable, to seek support and guidance. Sharing your challenges and problems with someone can lead to greater insight. You may think "how can a therapist understand my spouse and our relationship?" Actually, an outside person can often offer a valuable perspective that can only be gained through objectivity.

Service members and their families may also benefit from educational materials that aid in improving overall health and well-being. The Deployment Health Clinical Center (DHCC), a component agency of the Defense Centers of Excellence for Psychological Health and TBI, provides a list of programs and services that deal with post deployment adjustment, PTSD, combat trauma, military sexual trauma and other mental health issues.

\section{CONCLUSION}

In conclusion we can say that health is a state of complete physical, mental and social wellbeing. Mental health refers to your overall psychological well-being. Positive mental health is a state of well-being in which we realize our abilities, can cope with life's normal stresses, and can work regularly and productively. Good mental health is the foundation for a person's effective functioning. We can construct positivity and boost our mental health and wellbeing by some activities such as development of good relationship, Participation and sharing interests, contribution to community, challenge our self, dealing with daily psychological problems. Just as physical fitness helps our bodies to stay strong, mental fitness helps us to achieve and sustain a state of good mental health. When we are mentally healthy, we enjoy our life and environment, 


\section{Psychological Well-being among public and private undertakings in Aligarh}

and the people in it. Physical health can be determined by considering someone's height/weight ratio, their body mass index, their resting heart rate and recover time after exercise. Another term for physical health is physical wellbeing. Physical wellbeing is defined as something a person can achieve by developing all health-related components of his/her lifestyle. Physical activity and positive psychology are a match made in heaven - one focuses on the building of happy, fully functioning people and the other is a tried and tested avenue for creating such positive people. Maintaining physical health means employing preventive practices including good nutrition, exercise, sleep, and regular medical and dental check-ups. Mental and physical health is fundamentally linked. There are multiple associations between mental health and chronic physical conditions that significantly impact people's quality of life, demands on health care and other publicly funded services, and generate consequences to society. The relationship between mind and health is mediated both by our behavior and by biological connections between the brain and immune system. Strong family relationships are vital to overall health whether it is mental health or physical health.

\section{REFERENCES}

1. Canales, M. K. (2004). Taking care of self: health care decision making of American Indian women, Health Care for Women International, Vol. 25, 411-35

2. Engel, G. L. (1977). The need for a new medical model: a challenge for biomedicine. Science, Vol. 196, 129-36

3. Fredrickson, B. (2001). The role of positive emotions in positive psychology: the broaden and build theory of positive emotions. American Psychologist, 56 (3) 218-26

4. Herzlich, C. (1973). Health and Illness: A Social Psychological Analysis. London: Academic Press.

5. Kobasa, S., Maddi, S., Puccetti, M. and Zola, M. (1985) Effectiveness of hardiness, exercise and social support as resources against illness, Journal of Psychosomatic Research, Vol. 29, 525-33

6. Marks, D. F., Murray, M., Evans, B. \& Willig, C. (2000) Health Psychology: Theory, Research and Practice, London: Sage.

7. Martin, P. (1997). The sickening mind: brain, behavior, immunity and disease. London: Flamingo.

8. Moses, J., Steptoe, A., Mathews, A. and Edwards, S. (1989) The effects of exercise training on mental wellbeing in the normal population: a controlled trial. Journal of Psychosomatic Research, 33: 47-61.

9. Pierret (1995). The meaning of Illness: Anthropology, History and Sociology, Paris: Harwood Academic

10. Ratey, J. (2008) SPARKS: The Revolutionary New Science of Exercise and the Brain. New York: Little, Brown Company.

11. Radley, A. (1994) Making Sense of Illness: The Social Psychology of Health and Disease. London: Sage.

12. Seedhouse, D. (1986). Health: The Foundations for Achievement. Chichester: John Wiley. 